\title{
Atomistic Simulation Study of Spinel Oxides: Zinc Aluminate and Zinc Gallate
}

\author{
Ravindra Pandey, ${ }^{\dagger}$ Julian D. Gale, ${ }^{\ddagger}$ Suresh K. Sampath,${ }^{\dagger}$ and Jose M. Recio ${ }^{\S}$ \\ Department of Physics, Michigan Technological University, Houghton, Michigan 49931; \\ Department of Chemistry, Imperial College of Science, Technology, and Medicine, \\ South Kensington, SW7 2AY, London, United Kingdom; and \\ Departamento de Química Física y Analítica, Universidad de Oviedo, 33006-Oviedo, Spain
}

\begin{abstract}
Stoichiometric zinc aluminate $\left(\mathrm{ZnAl}_{2} \mathrm{O}_{4}\right)$ and zinc gallate $\left(\mathrm{ZnGa}_{2} \mathrm{O}_{4}\right)$ are simulated in the framework of the shell model, for which a new set of two-body interatomic potential parameters has been developed. Using these parameters, a reasonable prediction is made for elastic and dielectric constants of $\mathrm{ZnAl}_{2} \mathrm{O}_{4}$ and $\mathrm{ZnGa}_{2} \mathrm{O}_{4}$. Both oxides are stable against decomposition to the component oxides. The fitting of the potential energy surface of these oxides to the equation of state yields the bulk modulus and its pressure derivative. The bulk modulus is predicted to be higher in $\mathrm{ZnAl}_{2} \mathrm{O}_{4}$ as compared with that in $\mathrm{ZnGa}_{2} \mathrm{O}_{4}$, whereas the pressure derivative remains the same in both oxides. On the other hand, the octahedral and tetrahedral volumes of $\mathrm{ZnGa}_{2} \mathrm{O}_{4}$ are greater than those of $\mathrm{ZnAl}_{2} \mathrm{O}_{4}$. These differences in compressibility behavior can be attributed to the size difference between $\mathrm{Al}^{3+}$ and $\mathrm{Ga}^{3+}$ in the spinel oxides considered here. The calculated formation energies of the native defects suggest the preference of disorder in the cation sublattice over the Schottky and Frenkel defects. Although the degree of disorder is expected to be small, it is likely to influence the vacancy population in the lattice. Finally, deviations from stoichiometry are considered in which a preference for the dissolution of $\mathrm{Al}_{2} \mathrm{O}_{3} / \mathrm{Ga}_{2} \mathrm{O}_{3}$ via the formation of zinc vacancies is predicted relative to that of $\mathrm{ZnO}$ in $\mathrm{ZnAl}_{2} \mathrm{O}_{4} / \mathrm{ZnGa}_{2} \mathrm{O}_{4}$.
\end{abstract}

\section{Introduction}

$\mathrm{T}$ HE reflective optical properties of zinc aluminate $\left(\mathrm{ZnAl}_{2} \mathrm{O}_{4}\right)$, zinc gallate $\left(\mathrm{ZnGa}_{2} \mathrm{O}_{4}\right)$, and intermediate zinc aluminogallate spinel oxides have been investigated recently. ${ }^{1}$ Both oxides are structurally isomorphous, where $\mathrm{Al}^{3+}$ and $\mathrm{Ga}^{3+}$ are interchangeable. The optical bandgap of the polycrystalline $\mathrm{ZnAl}_{2} \mathrm{O}_{4}$ is $\sim 320 \mathrm{~nm}$ and of the $\mathrm{ZnGa}_{2} \mathrm{O}_{4}$ is $\sim 295 \mathrm{~nm}$. The absorbance spectra of these spinels show that they are highly reflective for wavelengths $(\lambda<300 \mathrm{~nm})$ in the ultraviolet (UV) region of the optical spectrum. Therefore, the paint developed ${ }^{2}$ from zinc-based spinel oxides provides a good thermal control coating. At present, pigments based on aluminum-doped $\mathrm{ZnO}$ that reflect light only from visible through the ultraviolet region of the spectrum are commonly used on spacecraft. Therefore,

K. E. Sickafus-contributing editor

Manuscript No. 189962. Received December 28, 1998; approved October 1, 1999 Presented at the 100th Annual Meeting of The American Ceramic Society, Cincinnati, OH, May 6, 1998 (Basic Science Division Special Session on Spinel Compounds: Structure and Property Relations, Paper No. BS13-017-98).

${ }^{\dagger}$ Michigan Technological University.

Imperial College of Science, Technology, and Medicine.

Universidad de Oviedo. it is expected that coatings of zinc-based spinels would be far superior as thermal control coatings for aerospace applications. ${ }^{3}$

Although extensive work involving both experimental and theoretical methods has been performed on spinel oxides, there is a lack of information about bulk and defect properties of $\mathrm{ZnAl}_{2} \mathrm{O}_{4}$ and $\mathrm{ZnGa}_{2} \mathrm{O}_{4}$. For example, the known properties of these materials are only the lattice constants ${ }^{4}$ and the absorbance spectra. ${ }^{1}$ We are aware of no extensive theoretical studies on these materials, except electronic structure calculations ${ }^{5}$ and the prediction of the stability of the normal spinel structure over the inverse structure for $\mathrm{ZnAl}_{2} \mathrm{O}_{4} \cdot{ }^{6}$ To provide a detailed knowledge of the crystalline and defect properties of these zinc-based spinel oxides, we have embarked upon a theoretical study based on both atomistic and first-principles methods. In this article, we present the results of an atomistic simulation study that includes derivation of interatomic potentials, determination of the equation of state and compressibility behavior at the octahedral and tetrahedral sites in the spinel lattice, and energetics of point defects in $\mathrm{ZnAl}_{2} \mathrm{O}_{4}$ and $\mathrm{ZnGa}_{2} \mathrm{O}_{4}$.

\section{Method}

The simulation of oxides using interatomic potentials is now a well-established field with the most common approach based on a fully ionic description of such materials. ${ }^{7}$ Quantum mechanical results have shown that many oxides can be genuinely considered as ionic, provided the formal oxidation state of the metal cation does not exceed $2+$. Even for oxidation states $>2+$, the ionic model is often a reasonable basis for interatomic potential models, because effects of covalency can be subsumed to the parameterization for closed-shell ions, such as those considered in this study. Hence, we have chosen to use a fully ionic description of the oxides simulated in the present study. The force field used in this work consists of a pairwise interaction energy that is composed of a Buckingham potential to model the short-range Pauli repulsion and the leading term of any dispersion energy, plus the Coulomb interaction.

$$
E_{i j}=A \exp \left(\frac{-r_{i j}}{\rho}\right)-C r_{i j}^{-6}+\frac{q_{i} q_{j}}{r_{i j}}
$$

where $E_{i j}$ is the interatomic potential, $A, \rho$, and $C$ constants that are determined empirically, and $q$ the change of the particles.

Because of the conditionally convergent nature of the electrostatic interaction, an Ewald sum is used to calculate the electrostatic energy and its derivatives. ${ }^{8}$ The partitioning between reciprocal and real space is chosen so as to minimize the total number of terms to be evaluated. ${ }^{9}$ Other interactions are summed directly in real space out to a cutoff of $12 \AA$, except for the exponential repulsion, which is truncated when it becomes less than the target accuracy for the Ewald sum. Ion dipolar polarizability also has been included through the use of the 
shell model. ${ }^{10}$ Here, a massless shell, on which all interatomic potentials act, is coupled by a harmonic spring to a core, i.e.,

$$
E_{\text {core-shell }}=\frac{1}{2} k r^{2}
$$

(where $k$ is the spring constant) from which it is Coulombically screened, yielding an environment-dependent ion polarizability. All structures have been optimized with respect to the asymmetric unit fractional coordinates and cell strains using analytical symmetry-adapted first and second derivatives within a Newton-Raphson procedure. All calculations have been performed using the program GULP. ${ }^{11}$

\section{Results and Discussion}

\section{(1) Derivation of Interatomic Potentials}

Although there are various existing transferable sets of interatomic potentials for oxides based on the ionic model, very few include all the relevant interactions needed for this study, particularly those between gallium and oxygen. Hence, we have generated an optimized set of potential parameters for the materials in this study. However, there is insufficient data for $\mathrm{ZnAl}_{2} \mathrm{O}_{4}$ and $\mathrm{ZnGa}_{2} \mathrm{O}_{4}$ to develop a reliable model because of the lack of known physical properties. To resolve the above problem, the interatomic potentials have been fitted in several stages. First, the oxygen-oxygen short-range potential has been taken from the work of Bush et al., ${ }^{12}$ who concurrently have fitted it to a wide range of oxides. In this potential, the oxygenoxygen repulsion results almost exclusively from the electrostatics, which, given that formal charges probably represent an overestimate, is quite reasonable. The dispersion energy term of the Buckingham potential (which has been allowed to fit freely in the work of Bush et al.) has a physically sensible value that accords well with quantum mechanical estimates based on embedded cluster calculations. ${ }^{13}$

To further reduce the number of free parameters to be determined for the target spinel materials, the oxygen-shellmodel parameters and the $\mathrm{Zn}-\mathrm{O}$ Buckingham potential were fitted to the hexagonal polymorph of $\mathrm{ZnO}$ (wurtzite), for which there is a wide range of known physical properties. Quantities included in the least-squares fit, in addition to the crystal structure, were the elastic constants $C_{11}, C_{12}, C_{13}, C_{55}$, and $C_{66}$, and the static and the high-frequency dielectric constants, both parallel and perpendicular to the $c$-axis. After the zinc and oxygen parameters were determined, based on $\mathrm{ZnO}$, they were then fixed, whereas the $\mathrm{Al}-\mathrm{O}$ and $\mathrm{Ga}-\mathrm{O}$ Buckingham potential parameters were determined by fitting to $\alpha-\mathrm{Al}_{2} \mathrm{O}_{3} / \mathrm{ZnAl}_{2} \mathrm{O}_{4}$ and $\mathrm{Ga}_{2} \mathrm{O}_{3} / \mathrm{ZnGa}_{2} \mathrm{O}_{4}$, respectively. In the case of $\mathrm{Al}-\mathrm{O}$, the elastic constants and static dielectric properties of corundum were included, as was the crystallographic information. The relaxedfitting algorithm was used in all parameter determinations. ${ }^{14}$ Here, an optimization of the crystal structure was performed at every stage of the least-squares procedure. This algorithm had the benefit that the fitted quantities became the changes in structural parameters rather than the forces calculated at the experimental structure. It was a superior procedure, because minimizing the forces did not guarantee to produce better results unless the second derivatives also were improved. Fur- thermore, this allowed all properties included in the fit to be properly determined about the energy minimum configuration rather than at the unrelaxed experimental geometry. The final interatomic potential parameters obtained for the spinel oxides considered here are given in Table I.

\section{(2) Perfect Lattice: Cohesive Properties}

The space group of the spinel-type structure is $F d 3 m$. The unit cell of a normal spinel (the type considered in this work) contains 32 oxygen anions in the positions of a cubic closepacked arrangement in which eight divalent cations are situated in one-eighth of the tetrahedral interstices, and 16 trivalent cations are situated in one-half of the octahedral interstices. The position of the oxygen ions in the unit cell is given by the internal parameter, $u$. Therefore, two parameters are needed to characterize the normal spinel structure, namely, $u$ and the unit-cell constant $a$. In the interatomic potential model used here, these two parameters are optimized simultaneously.

In both spinel oxides, our calculated values of $a$ and $u$ are within $2 \%$ of the corresponding experimental values (Table II). Much smaller errors would have been obtained by fitting the $\mathrm{Al}-\mathrm{O}$ and $\mathrm{Ga}-\mathrm{O}$ potentials to these structures while excluding the data for the parent binary oxides. However, this would have led to loss of accuracy in the description of the curvature of the potential-energy surface about the minimum. The ion size difference between $\mathrm{Ga}^{3+}$ and $\mathrm{Al}^{3+}$ is responsible for larger $a$ and smaller $u$ parameters in $\mathrm{ZnGa}_{2} \mathrm{O}_{4}$, as compared with $\mathrm{ZnAl}_{2} \mathrm{O}_{4}$. This is as expected, because, given that the divalent cation is the same in both spinels, $u$ should decrease when the size of the trivalent cation increases. ${ }^{15}$ For elastic and dielectric constants, no experimental data is available for comparison with the predicted values. However, these values appear to be reasonable when we compare them with those of similar spinel oxides, such as $\mathrm{MgAl}_{2} \mathrm{O}_{4}{ }^{16}$ and $\mathrm{ZnCr}_{2} \mathrm{O}_{4} \cdot{ }^{17}$ Also, the calculated lattice energy for both spinel oxides compares well with the experimental Born-Haber value of $\sim 204 \mathrm{eV}$ for $\mathrm{MgAl}_{2} \mathrm{O}_{4} \cdot{ }^{18}$

To further test the reliability of our potential model, we examine the stability of these spinel oxides with respect to their component oxides (see Table III). The calculated enthalpies of these reactions (obtained by taking the difference in lattice energies) are -1.88 and $-1.62 \mathrm{eV}$, respectively, showing that these spinels are predicted to be stable in our model. However, the calculated values are much larger than the corresponding value for $\mathrm{MgAl}_{2} \mathrm{O}_{4}$, which is a few tenths of an electron volt. ${ }^{18}$ Therefore, our static lattice calculations indicate a much higher stability of $\mathrm{ZnAl}_{2} \mathrm{O}_{4}$ and $\mathrm{ZnGa}_{2} \mathrm{O}_{4}$ relative to $\mathrm{MgAl}_{2} \mathrm{O}_{4}$. A recent quasi-hydrostatic powder X-ray diffractometry (XRD) study of $\mathrm{MgAl}_{2} \mathrm{O}_{4}$ predicts that it is stable with respect to its component oxides up to $65 \mathrm{GPa}$ at room temperature. ${ }^{19}$

\section{(3) Perfect Lattice: Equation of State}

Here, we analyze the crystalline response of both spinel oxides to hydrostatic pressure under static conditions, i.e., at zero temperature, neglecting zero-point contributions. Because there are no experimental data available on these oxides, our theoretical results are compared with well-established general trends found in other spinel-type oxides. ${ }^{4,15}$ Basically, the relevant properties that can be used to conduct such an analysis are (i) the bulk modulus $\left(B_{0}\right)$ and its pressure first derivative

Table I. Short-Range Potentials and Shell Model Parameters for $\mathrm{ZnAl}_{2} \mathrm{O}_{4}$ and $\mathrm{ZnGa}_{2} \mathrm{O}_{4}^{\dagger}$

\begin{tabular}{lrlccr}
\hline Bond & \multicolumn{1}{c}{$A(\mathrm{eV})$} & $\rho(\AA)$ & $C\left(\mathrm{eV} \cdot \AA^{6}\right)$ & $k\left(\mathrm{eV} \cdot \AA^{-9}\right)$ & $Y(\mathrm{e})$ \\
\hline $\mathrm{Al}_{\mathrm{s}}-\mathrm{O}_{\mathrm{s}}$ & 3829.69 & 0.248 & 0.0 & & \\
$\mathrm{Zn}_{\mathrm{c}}-\mathrm{O}_{\mathrm{s}}$ & 890.42 & 0.314 & 0.0 & & \\
$\mathrm{O}_{\mathrm{s}}-\mathrm{O}_{\mathrm{s}}$ & 25.41 & 0.694 & 32.32 & & \\
$\mathrm{O}_{\mathrm{s}}-\mathrm{Ga}_{\mathrm{c}}$ & 2339.78 & 0.274 & 0.0 & & \\
$\mathrm{Al}_{\mathrm{c}}-\mathrm{Al}_{\mathrm{s}}$ & & & & 425.26 & 2.96 \\
$\mathrm{O}_{\mathrm{c}}-\mathrm{O}_{\mathrm{s}}$ & & & & 24.85 & -2.82 \\
\hline${ }^{+} \mathrm{Host}$ lattice ions are $\mathrm{Zn}^{2+}, \mathrm{Al}^{3+}, \mathrm{Ga}^{3+}$, and $\mathrm{O}^{2-}$. "Subscript c refers to core and subscript s refers to shell
\end{tabular}


Table II. Calculated Bulk Properties of $\mathrm{ZnAl}_{2} \mathrm{O}_{4}$ and $\mathrm{ZnGa}_{2} \mathrm{O}_{4}$

\begin{tabular}{|c|c|c|c|c|}
\hline \multirow[b]{2}{*}{ Property } & \multicolumn{2}{|c|}{$\mathrm{ZnAl}_{2} \mathrm{O}_{4}$} & \multicolumn{2}{|c|}{$\mathrm{ZnGa}_{2} \mathrm{O}_{4}$} \\
\hline & Calculated & Experimental $^{\dagger}$ & Calculated & Experimental \\
\hline \multicolumn{5}{|c|}{ Structural parameters } \\
\hline$a(\AA)$ & 8.21 & 8.09 & 8.38 & 8.33 \\
\hline$u$ & 0.261 & 0.264 & 0.260 & 0.262 \\
\hline \multicolumn{5}{|c|}{ Elastic constants $\left(\times 10^{11}\right.$ dyne $\left.\cdot \mathrm{cm}^{-2}\left(10^{10} \mathrm{~Pa}\right)\right)$} \\
\hline$C_{11}$ & 34.18 & & 28.77 & \\
\hline$C_{12}$ & 24.68 & & 21.83 & \\
\hline$C_{44}$ & 15.04 & & 12.49 & \\
\hline \multicolumn{5}{|c|}{ Dielectric constants } \\
\hline$\varepsilon_{0}$ & 11.16 & & 13.72 & \\
\hline$\varepsilon_{\infty}$ & 5.11 & & 5.10 & \\
\hline
\end{tabular}

${ }^{\dagger}$ Experimental values are taken from Hill et al. ${ }^{4}$

$\left(B_{0}{ }^{\prime}\right)$, both evaluated at zero pressure; (ii) the octahedral and tetrahedral compressibilities of cations in the lattice; and (iii) the pressure dependence of the lattice parameter $u$ and of the two (divalent and trivalent) cation-oxygen bond lengths. These properties manifest interdependences, as have been clearly illustrated by Finger, Hazen, and Hofmeister ${ }^{15}$ in their comparative study of $\mathrm{MgAl}_{2} \mathrm{O}_{4}$ and magnetite with silicate spinels.

The polyhedral bulk moduli $\left(B_{0}\right)_{\text {oct }}$ and $\left(B_{0}\right)_{\text {tet }}$ are inverse of the octahedral and tetrahedral compressibilities, respectively, and are given as

$$
\begin{aligned}
& \left(B_{0}\right)_{\text {oct }}=-\frac{1}{V_{\text {oct }}}\left(\frac{\partial P}{\partial V_{\text {oct }}}\right)_{0} \\
& \left(B_{0}\right)_{\text {tet }}=\frac{1}{V_{\text {tet }}}\left(\frac{\partial P}{\partial V_{\text {tet }}}\right)_{0}
\end{aligned}
$$

where $V_{\text {oct }}$ and $V_{\text {tet }}$ are the corresponding volumes of the octahedral and tetrahedral interstices, and the derivatives are evaluated at zero pressure.

We first generate the potential-energy surface for both spinel oxides, in which we have considered the cell volumes ranging from $80 \%$ to $110 \%$ of the calculated equilibrium value, while relaxing the internal lattice parameter $u$ for each value of the cell volume. The energy surface then is used to obtain the volume dependence of pressure and the static equation-of-state (EOS) parameters. We have used numerical as well as several proposed empirical EOS fittings (see Francisco et al. ${ }^{20}$ for details) and have found consistency of the calculated parameters among the various fitting procedures. Integration of the empirical EOS allows us to reproduce the energy surface that is plotted with the calculated values in Fig. 1, which shows that the quality of the EOS fits is very good for both spinels. Once the equilibrium volumes at the desired pressures are computed, the remaining necessary properties can be obtained easily.

Table III. Reaction Energy of $\mathrm{ZnAl}_{2} \mathrm{O}_{4}, \mathrm{ZnGa}_{2} \mathrm{O}_{4}$, and

\begin{tabular}{|c|c|}
\hline Reaction & Reaction energy $(\mathrm{eV})$ \\
\hline $\begin{array}{l}\mathrm{Zn}_{\infty}^{2+}+\mathrm{O}_{\infty}^{2-} \rightarrow \mathrm{ZnO} \\
2 \mathrm{Al}_{\infty}^{3+}+3 \mathrm{O}_{\infty}^{2-} \rightarrow \mathrm{Al}_{2} \mathrm{O}_{3} \\
\mathrm{Zn}_{\infty}^{2+}+2 \mathrm{Al}_{\infty}^{3+}+4 \mathrm{O}_{\infty}^{2-} \rightarrow \mathrm{ZnAl}_{2} \mathrm{O}_{4}\end{array}$ & $\begin{array}{r}-39.70 \\
-158.38 \\
-199.96\end{array}$ \\
\hline $\begin{array}{l}\text { Enthalpy of the reaction } \\
\mathrm{ZnO}+\mathrm{Al}_{2} \mathrm{O}_{3} \rightarrow \mathrm{ZnAl}_{2} \mathrm{O}_{4}\end{array}$ & -1.88 \\
\hline $\begin{array}{l}\mathrm{Zn}_{\infty}^{2+}+\mathrm{O}_{\infty}^{2-} \rightarrow \mathrm{ZnO} \\
2 \mathrm{Ga}_{\infty}^{3+}+3 \mathrm{O}_{\infty}^{2-} \rightarrow \mathrm{Ga}_{2} \mathrm{O}_{3} \\
\mathrm{Zn}_{\infty}^{2+}+2 \mathrm{Ga}_{\infty}^{3+}+4 \mathrm{O}_{\infty}^{2-} \rightarrow \mathrm{ZnGa}_{2} \mathrm{O}_{4}\end{array}$ & $\begin{array}{r}-39.70 \\
-153.12 \\
-194.44\end{array}$ \\
\hline $\begin{array}{l}\text { Enthalpy of the reaction } \\
\mathrm{ZnO}+\mathrm{Ga}_{2} \mathrm{O}_{3} \rightarrow \mathrm{ZnGa}_{2} \mathrm{O}_{4}\end{array}$ & -1.62 \\
\hline
\end{tabular}
Their Component Oxides

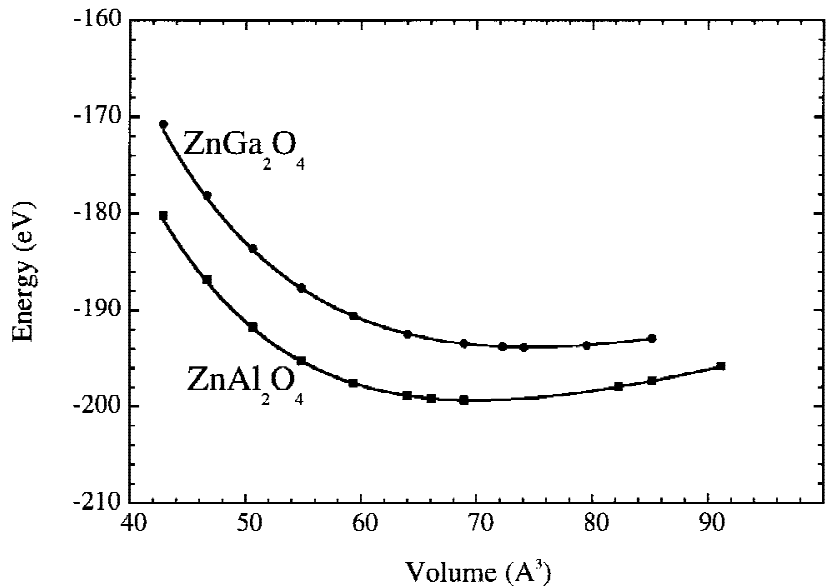

Fig. 1. Energy versus volume of (ם) $\mathrm{ZnAl}_{2} \mathrm{O}_{4}$ and (-) $\mathrm{ZnGa}_{2} \mathrm{O}_{4}$ according to our calculations and (-) the integrated Vinet equation of state.

Table IV includes bulk moduli, showing the compressibility behavior of the two spinels studied here. Accordingly, $\mathrm{ZnAl}_{2} \mathrm{O}_{4}$ and $\mathrm{ZnGa}_{2} \mathrm{O}_{4}$ exhibit different pressure behavior. The rigidity of the trivalent cations against deformation results in ion sizes that constitute an important factor in understanding the EOS of analogous spinel oxides. Thus, the local compressibilities at the octahedral sites in both crystals are unambiguously indicative of the importance of this factor. The higher octahedral volume $\left(V_{\text {oct }}\right)$ in $\mathrm{ZnGa}_{2} \mathrm{O}_{4}$ forces the tetrahedral volume $\left(V_{\text {tet }}\right)$ to be higher in this crystal than that in $\mathrm{ZnAl}_{2} \mathrm{O}_{4}$. The greater the volume of the interstice (for a fixed oxidation state) the lower the associated bulk modulus, ${ }^{15}$ as given by the corresponding $\left(B_{0}\right)_{\text {oct }}$ and $\left(B_{0}\right)_{\text {tet }}$ values. Moreover, the bulk moduli of these crystals are roughly the average of their respective $\left(B_{0}\right)_{\text {oct }}$ and $\left(B_{0}\right)_{\text {tet }}$ bulk moduli. Hence, the $\sim 15 \%$ higher $B_{0}$ value in $\mathrm{ZnAl}_{2} \mathrm{O}_{4}$ than in $\mathrm{ZnGa}_{2} \mathrm{O}_{4}$ can be traced back to the trivalent cation sizes. The pressure derivative of the bulk modulus $\left(B_{0}^{\prime}\right)$ remains almost the same in both crystals.

Different compressibilities of the octahedral and tetrahedral sites are related to the pressure dependence of the $u$ parameter in the lattice. It has been reported ${ }^{15}$ that a negative slope of the pressure $-u$ curve corresponds to the case where $\left(B_{0}\right)_{\text {oct }}$ is greater than $\left(B_{0}\right)_{\text {tet }}$. This has been confirmed by our calculations for both spinels (see Fig. 2 and Table IV). The variation of cation-oxygen bond lengths (i.e., $\mathrm{Zn}^{2+}-\mathrm{O}^{2-}, \mathrm{Al}^{3+}-\mathrm{O}^{2-}$, and $\mathrm{Ga}^{3+}-\mathrm{O}^{2-}$ ) with pressure is shown in Fig. 3. As expected, the cation oxidation state groups these bond lengths in two sets, namely divalent cation-oxygen and trivalent cation-oxygen. In each case, the bond lengths associated with $\mathrm{ZnAl}_{2} \mathrm{O}_{4}$ show a smaller variation with pressure than those associated with $\mathrm{ZnGa}_{2} \mathrm{O}_{4}$. These results are consistent with the various compressibilities predicted for the associated tetrahedral and octahedral interstices.

\section{Native Defects}

To evaluate native defect energies, calculations have been performed using the Mott-Littleton method. ${ }^{21}$ Here, the region

Table IV. Bulk Moduli and Volumes Related to Crystal Compressibility of $\mathrm{ZnAl}_{2} \mathrm{O}_{4}$ and $\mathrm{ZnGa}_{2} \mathrm{O}_{4}$

\begin{tabular}{lll}
\hline \multicolumn{1}{c}{ Property } & $\mathrm{ZnAl}_{2} \mathrm{O}_{4}$ & $\mathrm{ZnGa}_{2} \mathrm{O}_{4}$ \\
\hline$B_{0}(\mathrm{GPa})$ & 273 & 237 \\
$B_{0}^{\prime}$ & 3.4 & 3.5 \\
$\left(V_{0}\right)_{\text {oct }}\left(\AA^{3}\right)$ & 8.995 & 9.750 \\
$\left(V_{0}\right)_{\text {tet }}\left(\AA^{3}\right)$ & 4.478 & 4.654 \\
$\left(B_{0}\right)_{\text {oct }}(\mathrm{GPa})$ & 362 & 305 \\
$\left(B_{0}\right)_{\text {tet }}(\mathrm{GPa})$ & 207 & 180 \\
\hline
\end{tabular}




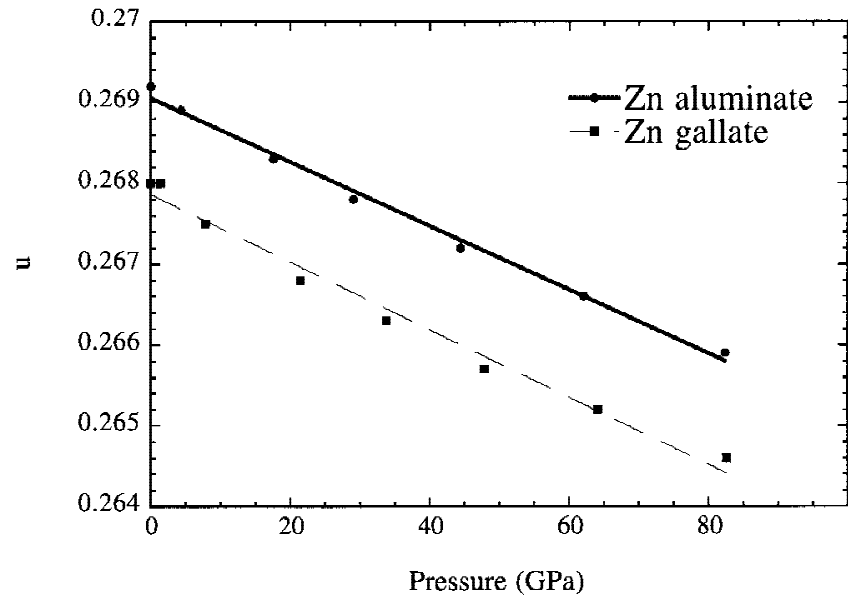

Fig. 2. Calculated pressure dependence of the internal lattice parameter $u$ in $\mathrm{ZnAl}_{2} \mathrm{O}_{4}$ and $\mathrm{ZnGa}_{2} \mathrm{O}_{4}$.

of the crystal surrounding the defect is divided in three spherical regions referred to as $1,2 \mathrm{a}$, and $2 \mathrm{~b}$. In region 1 , all interactions are treated directly at an atomistic level, and the ions are explicitly allowed to relax in response to the defect. Except in the case of very short-ranged defects, it is not generally possible to achieve the desired degree of convergence by increasing region 1 before running out of computer resources. Consequently, in region $2 \mathrm{a}$, some allowance is made for the relaxation of ions but in a way that is more approximate. In region $2 \mathrm{a}$, the ions are assumed to be situated in a harmonic well, and they subsequently respond to the electrostatic force of the defect species accordingly. This approximation is valid for small perturbations and, therefore, can be used when region 1 is sufficiently large. Beyond region $2 a$, in region $2 b$, the effect of the net charge of the defect polarizing the remainder of the crystal is evaluated out to convergence, using a partial transformation to reciprocal space, analogous to the Ewald method for the electrostatic energy. In the present work, a region 1 containing $\sim 300$ atoms is sufficient to converge the absolute defect energy to $\sim 0.01 \mathrm{eV}$, although relative energies are far more converged than this.

The Schottky defects in the lattice are formed by moving the constituent ions to the surface from their bulk sites. On the other hand, the Frenkel defects are pairs of vacancies and in-

Table V. Formation Energies (per defect) in $\mathrm{ZnAl}_{2} \mathrm{O}_{4}$ and $\mathrm{ZnGa}_{2} \mathrm{O}_{4}$

\begin{tabular}{|c|c|}
\hline Defect & $\begin{array}{c}\text { Formation } \\
\text { energy }(\mathrm{eV})\end{array}$ \\
\hline \multicolumn{2}{|c|}{$\mathrm{ZnAl}_{2} \mathrm{O}_{4}$} \\
\hline $\begin{array}{l}\mathrm{Zn}_{\mathrm{Al}}+\mathrm{Al}_{\mathrm{Zn}} \\
\mathrm{Zn}_{\mathrm{O}}+\mathrm{O}_{\mathrm{Zn}} \\
\mathrm{Al}_{\mathrm{O}}+\mathrm{O}\end{array}$ & $\begin{array}{r}1.7 \\
12.0 \\
19.3\end{array}$ \\
\hline \multicolumn{2}{|l|}{ Frenkel } \\
\hline Zinc & 3.9 \\
\hline Aluminum & 6.0 \\
\hline Oxygen & 5.9 \\
\hline Schottky & 2.8 \\
\hline \multicolumn{2}{|c|}{$\mathrm{ZnGa}_{2} \mathrm{O}_{4}$} \\
\hline $\begin{array}{l}\mathrm{Zn}_{\mathrm{Ga}}+\mathrm{Ga}_{\mathrm{Zn}} \\
\mathrm{Zn}_{\mathrm{O}}+\mathrm{O}_{\mathrm{Zn}} \\
\mathrm{Ga}_{\mathrm{O}}+\mathrm{O}_{\mathrm{Gn}}\end{array}$ & $\begin{array}{r}0.9 \\
11.2 \\
20.9\end{array}$ \\
\hline Frenkel & \\
\hline Zinc & 3.4 \\
\hline Gallium & 5.3 \\
\hline Oxygen & 5.2 \\
\hline Schottky & 2.4 \\
\hline
\end{tabular}

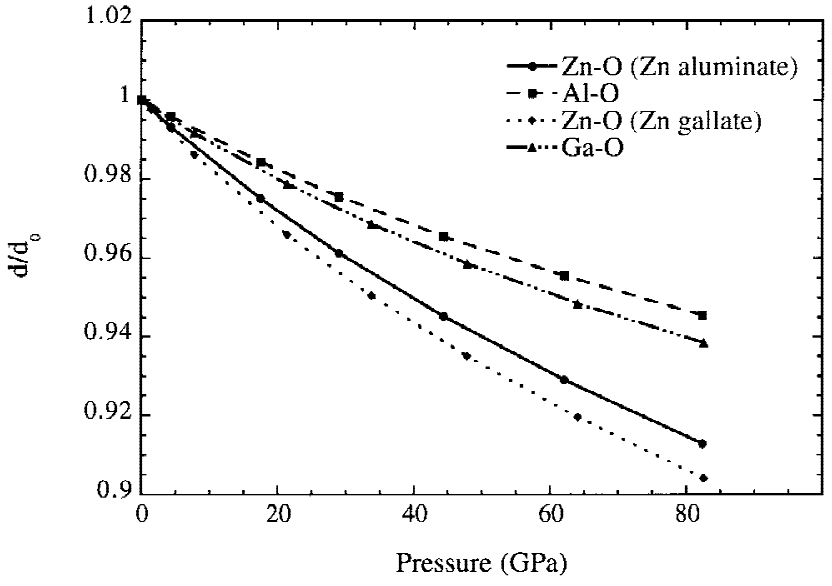

Fig. 3. Calculated pressure dependence of (normalized) cationoxygen bond lengths in $\mathrm{ZnAl}_{2} \mathrm{O}_{4}$ and $\mathrm{ZnGa}_{2} \mathrm{O}_{4}$. Here, $d_{0}$ refers to the corresponding zero pressure value.

terstitials of the same type of ion. Octahedral or tetrahedral interstitial sites are considered in the normal spinel lattice. However, as is the case with $\mathrm{MgAl}_{2} \mathrm{O}_{4},{ }^{22}$ the most stable positions of the interstitials are intermediate between conventional interstitial sites in these oxides.

The Schottky, Frenkel, and antisite formation energies given in Table $\mathrm{V}$ have been obtained from defect energy calculations of vacancies, interstitials, and antisites in the lattice. ${ }^{\text {II }}$

In $\mathrm{ZnAl}_{2} \mathrm{O}_{4}$, the Schottky defect is $\left(V_{\mathrm{Zn}}+2 V_{\mathrm{Al}}+4 V_{\mathrm{O}}\right)$; the Frenkel defect pairs are $\left(V_{\mathrm{Zn}}+\mathrm{Zn}_{i}\right),\left(V_{\mathrm{Al}}+\mathrm{Al}_{i}\right)$, and $\left(V_{\mathrm{O}}+\mathrm{O}_{i}\right)$; and the antisite pairs are $\left(\mathrm{Zn}_{\mathrm{Al}}+\mathrm{Al}_{\mathrm{Zn}}\right),\left(\mathrm{Zn}_{\mathrm{O}}+\mathrm{O}_{\mathrm{Zn}}\right)$, and $\left(\mathrm{Al}_{\mathrm{O}}+\mathrm{O}_{\mathrm{Al}}\right)$. In the defect configurations for $\mathrm{ZnGa}_{2} \mathrm{O}_{4}$, the aluminum atom is replaced by the gallium atom. As shown in Table V, the lowest formation energy per defect is for the antisite pair in the cation sublattice, which is followed by the Schottky and Frenkel pairs. The large formation energies for the antisite pairs involving cation and anion sublattices seems to preclude their occurrence as intrinsic point defects in these materials.

This ordering of formation energies follows the expected trend, because the magnitude of formation energy depends mainly on the extent of distortion introduced by individual defects in the lattice. In the present case, antisite disorder in the cation sublattice introduces the least distortion in the lattice compared with that introduced by either vacancies, interstitials, or antisites involving cation and anion sublattices. The occurence of disorder via the formation of zinc vacancies is predicted to be exothermic, in contrast to what has been reported for $\mathrm{ZnCr}_{2} \mathrm{O}_{4} \cdot{ }^{17}$ For example, this reaction in $\mathrm{ZnAl}_{2} \mathrm{O}_{4}$ with the reaction enthalpy of $-2.12 \mathrm{eV}$ is

$$
\mathrm{Zn}_{\mathrm{Zn}}^{\times}+V_{\mathrm{Al}}^{\prime \prime \prime} \rightarrow \mathrm{Zn}_{\mathrm{Al}}^{\prime}+V_{\mathrm{Zn}}^{\prime \prime}
$$

In $\mathrm{ZnGa}_{2} \mathrm{O}_{4}$, the reaction enthalpy is $-1.94 \mathrm{eV}$, whereas it is reported to be $+1.40 \mathrm{eV}$ in $\mathrm{ZnCr}_{2} \mathrm{O}_{4} \cdot{ }^{17}$ Therefore, it appears that the exchange disorder in the cation sublattice affects the vacancy populations in $\mathrm{ZnAl}_{2} \mathrm{O}_{4}$ and $\mathrm{ZnGa}_{2} \mathrm{O}_{4}$, although its extent is expected to be small, except at higher temperatures.

Likewise, the exchange disorder occurring via the formation of aluminum vacancies is

$$
\mathrm{Al}_{\mathrm{Al}}^{\times}+V_{\mathrm{Zn}}^{\prime \prime} \rightarrow \mathrm{Al}_{\mathrm{Zn}}+V_{\mathrm{Al}}^{\prime \prime \prime}
$$

However, this reaction is endothermic, with a large reaction enthalpy of $4.5 \mathrm{eV}$. The respective values in $\mathrm{ZnGa}_{2} \mathrm{O}_{4}$ and $\mathrm{ZnCr}_{2} \mathrm{O}_{4}{ }^{17}$ are 3.7 and $0.2 \mathrm{eV}$.

Finally, we consider the solution of $\mathrm{ZnO}$ in these spinel 
oxides, involving the formation of either oxygen vacancies or zinc interstitials as follows:

$$
\begin{aligned}
& \mathrm{ZnO}+\frac{1}{3} \mathrm{O}_{\mathrm{O}}^{\times}+\frac{2}{3} \mathrm{Al}_{\mathrm{Al}}^{\times} \rightarrow \frac{2}{3} \mathrm{Zn}_{\mathrm{Al}}^{\prime}+\frac{1}{3} V_{\mathrm{O}}^{\cdot \cdot}+\frac{1}{3} \mathrm{ZnAl}_{2} \mathrm{O}_{4} \quad E=1.6 \mathrm{eV} \\
& \mathrm{ZnO}+\frac{1}{2} \mathrm{Al}_{\mathrm{Al}}^{\times} \rightarrow \frac{1}{2} \mathrm{Zn}_{\mathrm{Al}}^{\prime}+\frac{1}{4} \mathrm{Zn}_{i}+\frac{1}{4} \mathrm{ZnAl}_{2} \mathrm{O}_{4} \quad E=2.2 \mathrm{eV} \\
& \mathrm{ZnO}+\frac{1}{3} \mathrm{O}_{\mathrm{O}}^{\times}+\frac{2}{3} \mathrm{Ga}_{\mathrm{Ga}}^{\times} \rightarrow \frac{2}{3} \mathrm{Zn}_{\mathrm{Ga}}^{\prime}+\frac{1}{3} V_{\mathrm{O}}^{\cdot}+\frac{1}{3} \mathrm{ZnGa}_{2} \mathrm{O}_{4} \quad E=1.4 \mathrm{eV} \\
& \mathrm{ZnO}+\frac{1}{2} \mathrm{Ga}_{\mathrm{Ga}}^{\times} \rightarrow \frac{1}{2} \mathrm{Zn}_{\mathrm{Ga}}^{\prime}+\frac{1}{4} \mathrm{Zn}_{i} \cdot \frac{1}{4} \mathrm{ZnGa}_{2} \mathrm{O}_{4} \quad E=1.9 \mathrm{eV}
\end{aligned}
$$

Similarly $\mathrm{Al}_{2} \mathrm{O}_{3} / \mathrm{Ga}_{2} \mathrm{O}_{3}$ can be dissolved in $\mathrm{ZnAl}_{2} \mathrm{O}_{4} /$ $\mathrm{ZnGa}_{2} \mathrm{O}_{4}$ via the formation of either zinc vacancies or oxygen interstitials.

$$
\begin{aligned}
& \mathrm{Al}_{2} \mathrm{O}_{3}+\frac{3}{4} \mathrm{Zn}_{\mathrm{Zn}}^{\times} \rightarrow \frac{1}{2} \mathrm{Al}_{\mathrm{Zn}}^{\cdot}+\frac{1}{4} V_{\mathrm{Zn}}^{\prime \prime}+\frac{3}{4} \mathrm{ZnAl}_{2} \mathrm{O}_{4} \quad E=-0.9 \mathrm{eV} \\
& \mathrm{Al}_{2} \mathrm{O}_{3} \rightarrow \frac{2}{3} \mathrm{Al}_{\mathrm{Zn}}+\frac{1}{3} \mathrm{O}_{i}^{\prime \prime}+\frac{2}{3} \mathrm{ZnAl}_{2} \mathrm{O}_{4} \quad E=1.5 \mathrm{eV} \\
& \mathrm{Ga}_{2} \mathrm{O}_{3}+\frac{3}{4} \mathrm{Zn}_{\mathrm{Zn}}^{\times} \rightarrow \frac{1}{2} \mathrm{Ga}_{\mathrm{Zn}}+\frac{1}{4} V_{\mathrm{Zn}}^{\prime \prime}+\frac{3}{4} \mathrm{ZnGa}_{2} \mathrm{O}_{4} \quad E=0.9 \mathrm{eV} \\
& \mathrm{Ga}_{2} \mathrm{O}_{3} \rightarrow \frac{2}{3} \mathrm{Ga}_{\mathrm{Zn}}+\frac{1}{3} \mathrm{O}_{i}^{\prime \prime}+\frac{2}{3} \mathrm{ZnGa}_{2} \mathrm{O}_{4} \quad E=1.1 \mathrm{eV}
\end{aligned}
$$

Based on the magnitude of the reaction enthalpy $(E)$, calculations predict that the dissolution of trivalent cation oxides $\left(\mathrm{Al}_{2} \mathrm{O}_{3} / \mathrm{Ga}_{2} \mathrm{O}_{3}\right)$ via the formation of zinc vacancies (Eqs. (9) and (11)) is much easier in the lattice as compared with that of the divalent cation oxide $(\mathrm{ZnO})$. Furthermore, only a small amount of $\mathrm{ZnO}$ can be dissolved in the spinel oxides considered here, and the dissolution is expected to be accommodated by the formation of oxygen vacancies in the lattice. Therefore, the calculated results corroborate the known facts about the higher solubility of $\mathrm{B}_{2} \mathrm{O}_{3}$ relative to $\mathrm{AO}$ in the spinel $\mathrm{AB}_{2} \mathrm{O}_{4}$ crystals.

\section{Summary}

We have developed a set of interatomic potentials for $\mathrm{ZnAl}_{2} \mathrm{O}_{4}$ and $\mathrm{ZnGa}_{2} \mathrm{O}_{4}$. In the absence of relevant data for both spinel oxides, the potential parameters have been fitted concurrently to the structural parameters, elastic and dielectric constants, of $\mathrm{ZnO}, \mathrm{Al}_{2} \mathrm{O}_{3}, \mathrm{Ga}_{2} \mathrm{O}_{3}, \mathrm{ZnAl}_{2} \mathrm{O}_{4}$, and $\mathrm{ZnGa}_{2} \mathrm{O}_{4}$. The predicted values of the elastic and dielectric constants for both spinel oxides compare well with those of analogous spinel oxides. Both oxides are stable with respect to their component oxides. Their response to hydrostatic pressure also follows the general trend of other similar spinels. The bulk modulus for $\mathrm{ZnAl}_{2} \mathrm{O}_{4}$ is higher than that of $\mathrm{ZnGa}_{2} \mathrm{O}_{4}$, whereas the octahedral and tetrahedral volumes of $\mathrm{ZnGa}_{2} \mathrm{O}_{4}$ are greater than those of $\mathrm{ZnAl}_{2} \mathrm{O}_{4}$. These differences can be attributed to the size difference of $\mathrm{Al}^{3+}$ and $\mathrm{Ga}^{3+}$.

Defect energy calculations based on the Mott-Littleton methodology predict the dominance of disorder in the cation sublattice relative to the Schottky and Frenkel defects in both spinels. In nonstoichiometric $\mathrm{ZnAl}_{2} \mathrm{O}_{4}$, the dissolution of $\mathrm{Al}_{2} \mathrm{O}_{3}$ is favorable as compared with that of $\mathrm{ZnO}$. Similar results have been found for $\mathrm{ZnGa}_{2} \mathrm{O}_{4}$. The calculated reaction enthalpies suggest that the formation of vacancies is preferable over the formation of interstitials to accomodate deviations from stoichiometry in the spinel lattice.

Acknowledgments: Helpful discussions with James F. Cordaro, QivaStar, Inc., Ridgecrest, CA, are acknowledged. JMR is grateful to the Spanish DGICYT, Project No. PB96-0559, for financial support, and JDG acknowledges the Royal Society for a University Research Fellowship.

\section{References}

${ }^{1}$ S. K. Sampath and J. F. Cordaro, "Optical Properties of Zinc Aluminate, Zinc Gallate, and Zinc Aluminogallate Spinels," J. Am. Ceram. Soc., 81, 649-54 (1998)

${ }^{2}$ Invented by J. F. Cordaro while a member of the academic staff of Michigan Technological University. Licensed for research purposes to Michigan Technological University. Developed by J. F. Cordaro of QivaStar, Inc., Ridgecrest, CA, and L. E. Long of Hughes Space and Communications Co., El Segundo, CA. U.S. Pat. No. 5807 909, Sept. 15, 1998.

${ }^{3}$ QivaStar, Inc., Ridgecrest, CA, and Hughes Space and Communications Co. El Segundo, CA. U.S. Pat. No. 5820 669, Oct. 13, 1998.

${ }^{4}$ R. J. Hill, J. R. Craig, and G. V. Gibbs, "Systematics of the Spinel Structure Type," Phys. Chem. Miner., 4, 317-39 (1979).

${ }^{5}$ S. K. Sampath, D. G. Kanhere, and R. Pandey, "Electronic Structure of Spinel Oxides: Zinc Aluminate and Zinc Gallate," J. Phys.: Condens Matter, 11 3635-44 (1999)

${ }^{6}$ A. N. Cormack, G. V. Lewis, S. C. Parker, and C. R. A. Catlow, "On the Cation Distribution of Spinels," J. Phys. Chem. Solids, 49 [1] 53-57 (1988).

${ }^{7}$ C. R. A. Catlow, C. M. Freeman, M. S. Islam, R. A. Jackson, M. Leslies, and S. M. Tomlinson, "Interatomic Potentials for Oxides," Philos. Mag. A, 58, 123 (1988).

${ }^{8}$ M. P. Tosi, "Cohesion of Ionic Solids in the Born Model," Solid State Phys., 16, 1 (1964)

${ }^{9}$ R. A. Jackson and C. R. A. Catlow, "Computer Simulation Studies of Zeolite Structure," Mol. Simul., 1, 207 (1988).

${ }^{10}$ B. G. Dick and A. W. Overhauser, "Theory of the Dielectric Constants of Alkali Halide Crystals," Phys. Rev., 112 [1] 90-103 (1958).

${ }^{11}$ J. D. Gale, "GULP: A Computer Program for the Symmetry-Adapted Simulation of Solid," J. Chem. Soc. Faraday Trans., 93, 629 (1997).

${ }^{12}$ T. S. Bush, J. D. Gale, C. R. A. Catlow, and P. D. Battle, "Self-Consistent Interatomic Potentials for the Simulation of Binary and Ternary Oxides," $J$ Mater. Chem., 4, 83 (1994).

${ }^{13}$ P. W. Fowler and N. C. Pyper, "In-Crystal Ionic Polarizabilities Derived by Combining Experimental and ab Initio Results," Proc. R. Soc. London A, $\mathbf{3 9 8}$ 377-93 (1985).

14J. D. Gale, "Empirical Potential Derivation for Ionic Materials," Philos. Mag. B., 73, 3 (1995)

${ }^{15}$ L. W. Finger, R. M. Hazen, and A. M. Hofmeister, "High-Pressure Crysta Chemistry of Spinel $\left(\mathrm{MgAl}_{2} \mathrm{O}_{4}\right)$ and Magnetic $\left(\mathrm{Fe}_{3} \mathrm{O}_{4}\right)$ : Comparisons with Silicate Spinels," Phys. Chem. Miner., 13, 215-20 (1986).

${ }^{16}$ G. V. Lewis and C. R. A. Catlow, "Potential Models for Ionic Oxides," J. Phys. C: Solid State Phys., 18, 1149 (1985).

${ }^{17}$ R. W. Grimes, D. J. Binks, and A. B. Lidiard, "The Extent of Zinc Oxide Solution in Zinc Chromate Spinel," Philos. Mag. A., 72, 651-68 (1995).

${ }^{18}$ M. Catti, G. Dovesi, and M. Causa, "Quantum-Mechanical Calculation of the Solid State Equilibrium $\mathrm{MgO}+\alpha-\mathrm{Al}_{2} \mathrm{O}_{3} \leftrightarrow \mathrm{MgAl}_{2} \mathrm{O}_{4}$ (Spinel) versus Pressure," Phys. Rev. B: Condens Matter, 49 [20] 14179-87 (1994).

${ }^{19}$ M. B. Kruger, J. H. Nguyen, W. Caldwell, and R. Jeanolz, "Equation of State of $\mathrm{MgAl}_{2} \mathrm{O}_{4}$ Spinel to $65 \mathrm{GPa}$," Phys. Rev. B: Condens Matter, 56, 1-4 (1994).

${ }^{20}$ E. Francisco, J. M. Recio, M. A. Blanco, A. M. Pendas, and A. Costales, "Quantum-Mechanical Study of Thermodynamic and Bonding Properties of $\mathrm{MgF}_{2}$, , J. Phys. Chem. A, 102, 1595-601 (1998).

${ }^{21}$ C. R. A. Catlow and W. C. Mackrodt, Lectures Notes in Physics, Vol. 166, Ch. 1, Springer, Berlin, 1982

${ }^{22}$ S. P. Chen, M. Yan, J. D. Gale, R. W. Grimes, R. Devanathan, K. E. Sickafus, N. Yu, and M. Nastasi, "Atomistic Study of Defect, Metastable, and 'Amorphous' Structures of $\mathrm{MgAl}_{2} \mathrm{O}_{4}$," Philos. Mag. Lett., 73, 51-62 (1996). 